\title{
El principio protestante y el protestantismo en la reflexión de Paul Tillich
}

\author{
Rafael Niño de Zepeda \\ UNIVERSIDAD CATÓLICA SILVA HENRÍQUEZ \\ rninodez@ucsh.cl
}

Resumen: Paul Tillich es uno de los teólogos que ha expresado con mayor claridad lo que significa ser protestante. El principio protestante y el protestantismo son dos conceptos que han estado presentes a lo largo de todo su historial como teólogo luterano, no solo en sus reflexiones teológicas y filosóficas, sino también en sus decisiones biográficas. El principio protestante, comprendido como la justificación por la sola gracia y la experiencia de la majestad de Dios en todos los ámbitos de la vida trasciende al protestantismo, comprendiendo esto último como una realización histórica del principio protestante. En este artículo trato de presentar estos dos conceptos desde el entramado de las principales líneas de reflexión y de las experiencias vitales que se encuentran consignados en los escritos de Tillich.

Palabras clave: Protestantismo, kairos, teonomía, demoníaco, gracia, justificación.

Abstract: Paul Tillich is one of the theologians who has more clearly expressed what it means to be a Protestant. The Protestant principle and Protestantism are two concepts that have been present throughout his history as a Lutheran theologian, not only in his theological and phylosophical thought, but also in his biographical decisions. The protestant principle, understood as the justification by grace alone and the experience of the majesty of God in all spheres of life transcend protestantism, understanding it as a historical realization of the protestant principle. In this article $Y$ try to present both concepts from the framework of the main reflection lines and vital experiences which are stated in the writings of Tillich.

Key words: Protestantism, kairos, theonomy, demonic, grace, justification. 


\section{INTRODUCCIÓN}

Este año se conmemora los 500 años del inicio de la reforma protestante, naturalmente surge en estos días un interés especial por comprender este proceso, que tuvo consecuencias insospechadas para el mismo Lutero. Creo que recurrir a las reflexiones de Paul Tillich es un buen camino para quienquiera comprender qué es el protestantismo en sus aspectos esenciales. Él se ha destacado por su profunda y certera reflexión sobre lo que significa ser protestante. Entrega elementos claves para comprender lo que es el movimiento protestante y su esencia -el principio protestante; $y$ viceversa, estas dos ideas son centrales para comprender su propia teología y su vida-.

En efecto, el principio protestante y la identificación personal con el protestantismo están presentes a lo largo de la trayectoria teológica de Tillich. El ser luterano lo identifica en su integridad. Así lo señala en su ensayo autobiográfico titulado On the Boundary (En la frontera): "Yo, yo mismo, pertenezco al luteranismo por nacimiento, educación, experiencia religiosa, y reflexión teológica [...] La substancia de mi religión es y permanecerá siendo luterana [...] No solamente mi pensamiento teológico, sino también el filosófico expresa la substancia luterana”'

En las páginas siguientes intentaré identificar los elementos centrales del concepto principio protestante y las implicancias teológicas y biográficas en nuestro autor. No se trata de extraer desde sus escritos los conceptos claves para definirlos y analizarlos, sino más bien de comprender el principio protestante y el protestantismo dentro del entramado de algunos de sus escritos y sus opciones vitales. La intención del presente artículo se puede concretar en una pregunta y un objetivo. La pregunta es ¿cuál es el significado del principio protestante y el protestantismo en la reflexión teológica de P. Tillich?, y el objetivo consiste en mostrar que el principio protestante no es un concepto más dentro de lo que podemos denominar como su sistema teológico, sino que es la fuente que determina una manera comprender la relación con Dios y con el mundo.

1 "I, myself, belong to Lutheranism by birth, education, religious experience, and theological reflection [...] The substance of my religion is and remains Lutheran [...] Not only my theological, but also my philosophical thinking expresses the Lutheran substance" (P. TILLICH, The Interpretation of History [Charles Scribner's Sons, New York, 1936] 54). (La traducción es propia, como todas las restantes traducciones en el texto). 
Para utilizar las mismas palabras de Tillich, es el poder del principio protestante $^{2}$ que condiciona una manera de ver la realidad. Pretendo mostrar aquí cómo el principio protestante se encuentra presente en la base del sistema de conceptos de la reflexión tillichiana. A través del principio protestante podremos entender las opciones de vida de nuestro autor, así como también el significado y las relaciones entre sus conceptos claves. Comenzaré por un intento de comprensión del principio protestante, continuaré con sus implicancias teológicas en relación con otros conceptos claves y en relación con la pregunta por el futuro del protestantismo, para concluir con una mirada en perspectiva más ecuménica.

\section{EL PRINCIPIO PROTESTANTE}

Tillich utiliza la expresión principio protestante para indicar la doctrina central y universal del protestantismo. Este principio no es una especial idea religiosa, ni depende del aumento o disminución de la experiencia espiritual, "[e]s el criterio último de toda experiencia religiosa y toda experiencia espiritual; yace en su base, estando o no consciente de ello"3.

Pero ¿qué es precisamente el principio protestante? En el ensayo The end of the Protestant Era? (¿El fin de la era protestante?) podemos encontrar los elementos centrales de su comprensión del principio protestante.

El principio central del Protestantismo es la doctrina de la justificación por la gracia, lo cual significa que ningún individuo y ningún grupo humano puede pretender una dignidad divina por los logros morales, por su poder sacramental, por su santidad, o por su doctrina. $\mathrm{Si}$, consciente o inconscientemente, ellos pretenden tal cosa, el Protestantismo exige que sean desafiados por la protesta profética, que da a Dios solamente la absolutez y la santidad y niega cualquier pretensión de orgullo humano. Esta protesta contra sí mismo sobre la base de una experiencia de la majestad de Dios constituye el principio Protestante [...] Ello implica que no puede haber un sistema sagrado, eclesiástico o político; que no puede haber una jerarquía

2 Cfr. P. TILLICH, The Protestant Era (The University of Chicago Press, Chicago, 1957)169.

3 "It is the ultimate criterion of all religious and all spiritual experiences; it lies at their base, whether they are aware of it or not" (P. Tillich, The Protestant..., viii). 
sagrada con autoridad absoluta; y que no puede haber una verdad en la mente humana que sea verdad divina en sí misma" ${ }^{4}$.

Esta cita comienza mencionando la conocida doctrina luterana de la justificación, la cual no es, para Tillich, solo una doctrina; es más bien un principio, el principio universal de la teología protestante. Ahora bien, según nuestro autor es necesario aclarar algunos aspectos de la formulación original de este principio, que llevaron posteriormente a ciertos malentendidos. En la lucha contra Roma -como se expresa Tillich- esta doctrina luterana básica terminó comprendiéndose como la justificación por la fe-y no por las obras-. Esto ha conducido a una gran confusión. La fe llegó a ser entendida como la causa de la justificación de Dios, lo que significa que los actos morales y rituales de la enseñanza católica, contra los cuales luchaba Lutero, son reemplazados por el acto de la fe, entendido como el trabajo intelectual de aceptación de una doctrina; habría que entender, entonces, que Lutero cayó en lo mismo que criticó. Al contrario, Tillich puntualiza que no es la fe sino la gracia la causa de la justificación. La misma fe es un regalo de la gracia. Por tanto, es necesario reemplazar la expresión justificación por la fe por justificación por la gracia a través de la $f e^{5}$, o simplemente justificación por la gracia. Ahora bien, el principio protestante no es solo una doctrina fundamental, sino también actitud y una exigencia: la protesta profética contra cualquier identificación de la gracia con alguna realidad visible, incluyendo a la misma iglesia en su aspecto visible ${ }^{6}$. En este sentido, Tillich no evita la denominación de protestante, con orgullo se denomina a sí mismo como un protestante, alguien que está en permanente protesta

4 "The central principle of Protestantism is the doctrine of justification by grace alone, which means that no individual and no human group can claim a divine dignity for its moral achievements, for its sacramental power, for its sanctity, or for its doctrine. If consciously or unconsciously, they make sach a claim, Protestantism requires that they be challenged by the prophetic protest, which gives God alone absoluteness and sanctity and denies every claim of human pride. This protest against itself on the basis of an experience of God's majesty constituyes the Protestant principle [...] It implies that there cannot be a sacred system, ecclesiastical or political; that there cannot be a sacred heirarchy with absoute authority; and that there cannot be a truth in human minds which is divine truth in itself" (P. Tillich, The Protestant..., 226).

5 Cfr. P. TILLICH, Systematic Theology III (The University of Chicago Press, Chicago, 1963), 224.

6 Cfr. P. TILLICH, The Protestant..., xvii. 
contra cualquiera divinización de alguna realidad temporal; se trata de una protesta profética que tiene que hacerse presente siempre frente a las ambigüedades del presente y ante cualquier realidad temporal que se alce como divina, que se eleve a la esfera de lo Incondicionado.

\section{EL PRINCIPIO PROTESTANTE Y CONCEPTOS PRINCIPALES}

El principio protestante ha tenido una importancia central en su biografía como teólogo y ha sido determinante para su reflexión teológica. En efecto, desde los comienzos de su desarrollo como teólogo, Tillich es consciente de la centralidad del principio protestante. Siendo aún estudiante formó parte de un grupo de estudiantes y docentes jóvenes, influidos por el profesor Martin Kaehler. Ahí desarrollaron una nueva comprensión del principio protestante, llegando a lo que Tillich denominó como una interpretación radical de la justificación por la fe (gracia) $)^{7}$. Esta interpretación radical se fue profundizando en su comprensión misma como también, y sobre todo, en sus consecuencias, que se plasmaron en la creación de una interpretación religiosa protestante de la historia. Tal interpretación la desarrolló a través de tres líneas, o conceptos principales: la teonomía, el kairos y lo demoníaco.

En cuanto al primero de estos conceptos principales, la teonomía, hay que decir en primer lugar que se enmarca en una interpretación teológica de la relación entre la religión y la cultura, es decir, en una teología de la cultura. Tillich concibe la teonomía y el marco teológico que los sustenta como una consecuencia del principio protestante. Su raciocinio es el siguiente: la gracia es la que justifica al hombre en su condición pecadora. El hombre pecador es declarado justo por Dios. Se trata de un acto divino libre y gratuito, no de un merecimiento por las obras del hombre. Entonces el hombre justificado no deja de ser pecador. Pues bien, este raciocinio lo extiende a toda la realidad más allá del individuo: así como el hombre en su condición de pecador no ha perdido su relación con Dios, toda la realidad, tal como es, tiene relación con la gracia, con lo Incondicionado, incluyendo la esfera no religiosa. En palabras de Tillich: "la interpretación radical y universal de la idea de la justificación a través de la fe tuvo importantes consecuencias teológicas más allá de lo personal. Si es válido, ningún reino de la vida puede existir

7 Cfr. P. TILLICH, The Protestant ..., xi. 
sin relación con algo incondicionado, con una preocupación última”. Consecuentemente, entonces, la religión es omnipresente en cualquier creación cultural, siendo la religión la sustancia de la cultura, de las formas culturales; la religión no es una esfera especial ni una función de la vida del hombre, sino que es la dimensión de profundidad de todas las funciones de la vida. Esta es la idea fundamental que expresó en su primera conferencia dictada en 1919 bajo el título Über die Idee einer Theologie der Kultur (Sobre la idea de una teología de la cultura). En el contexto de estos conceptos Tillich va a desarrollar lo que se conoce como una teología de la cultura, basada en su conocida fórmula: "la cultura es una forma o expresión de la religión, y la religión es la substancia (Inhalt) de la cultura" ". Esta relación puede hacerse efectiva en tres situaciones distintas: la autonomía, la heteronomía y la teonomía. La primera se realiza cuando la cultura (las formas) no manifiestan su substancia religiosa orientándose exclusivamente hacia la esfera de lo condicionado, esta es la situación que predomina hoy en Occidente desde la revolución industrial; la heteronomía es el intento de la religión de dominar la creatividad de la cultura autónoma desde fuera, se hace efectiva cuando la religión se identifica con una o algunas formas particulares, sin relación con su substancia, sacralizando algunas formas culturales. Según Tillich, esta situación predominó a finales de la Edad Media cuando la Iglesia se erigió como un poder sagrado que controló y reprimió cualquier legítima autonomía cultural y social; y, por último, la teonomía, cuando la cultura se hace transparente a su substancia religiosa, es decir, cuando el significado último de la existencia brilla a través de las formas finitas del pensamiento y la acción. La teonomía puede hacerse realidad solo fragmentariamente en la historia. El principio protestante rechaza la heteronomía, así como también la autonomía autocomplaciente, en cambio reclama la autotrascendencia autónoma, o teonomía.

El segundo concepto, el kairos, describe el momento en que lo eterno irrumpe en lo temporal, estando este último preparado para recibirlo, es

8 "The radical and universal interpretation of the idea of justification through faith had important theological consequences beyond the personal. If it is valid, no realm of life can exist without relation to something unconditional, to an ultimate concern" (P. TILLICH, The Protestant ..., xi).

9 "culture is a form or expression of religión, and religion is the substance (Inhalt) of culture" (P. TILLICH, What is Religion? [ Harpen \& Row Publishers, New York, 1969] 73). 
el tiempo especial, pleno. Este concepto fue central en los inicios de su reflexión teológica. Tillich tenía la certeza de vivir un kairos en la situación social y política de Alemania luego de la primera guerra. La derrota de la guerra, la revolución de 1918 que destronó al Kaiser, seguido de la república democrática bajo la dirección de los socialdemócratas creó un clima especial en Alemania de esos años, que luego de la guerra estuvo marcada por la pobreza en las calles de Berlín, la inestabilidad social y el pesimismo acerca del futuro. Todo este clima social, político y cultural impulsó la creación de un círculo de estudios denominado, justamente, como Círculo Kairos, en el cual Tillich participó activamente. Era un grupo de intelectuales que querían interpretar la situación presente sobre la base de los eventos mundiales vistos a la luz del criticismo de la burguesía del siglo XIX y comienzos del XX, y sobre todo con la ayuda de las categorías derivadas del principio protestante ${ }^{10}$.

En efecto, Tillich creyó vivir un tiempo especial (kairos), una oportunidad de síntesis entre el cristianismo y el socialismo en pos de un nuevo orden social. El socialismo debía ser entendido como comienzo hacia una nueva teonomía; y más que un sistema económico, un sistema de existencia que debía someterse bajo el juicio crítico profético de la expectación del kairos. Pues la categoría del kairos previene de identificar algún orden social con la realización tal como es significada por el Reino de Dios; al contrario, llama a mantenerse en una actitud de demanda y expectación de un Reino de Dios que permanecerá siempre como trascendente, pero al mismo tiempo como un juicio a una forma dada de sociedad.

En cuanto al tercer concepto, lo demoníaco, hay que destacar que es uno de los más característicos y originales de Tillich. Quiere expresar la ambigüedad de la realidad, la mezcla confusa de lo destructivo con lo creativo, de la luz con la oscuridad. Lo demoníaco caracteriza la totalidad de la realidad. Está en el arte, la religión, la política, etc. Esta categoría fue fundamental para interpretar la situación histórica y cultural de Alemania después de la guerra. El kairos en el cual creyeron vivir en ese entonces llamaba a vencer las demonías tanto del capitalismo como del nacionalismo y el secularismo. Estos eran denominados como las demonías del presente ${ }^{11}$. Lo demoníaco fue una importante categoría

10 Cfr. P. TILLICH, The Protestant..., xiii.

11 Cfr. P. TILLICH, The Interpretation ..., 115 ss. 
utilizada por Tillich en la etapa de su vida denominada como el periodo alemán, que duró hasta cuanto se vio obligado a dejar su patria en 1933 a causa de la persecución del régimen nazi. Ahora bien, es necesario aclarar que lo demoníaco no es lo satánico. Este último es la existencia de lo absolutamente destructivo, mientras que lo demoníaco es lo ambiguo, lo creativo destructivo inseparable y simultáneo. Para remontarse al origen de este concepto hay que llegar al místico luterano Jacob Boehme y el filósofo romántico Schelling. Para ambos filósofos luteranos existen dos fuerzas opuestas: lo creativo y lo destructivo, la luz y la oscuridad, provenientes del fondo del ser de las cosas, el cual es al mismo tiempo el fundamento y el abismo. Estas fuerzas se encuentran en Dios en unidad, pero en la existencia se independizan relativamente; entonces en las cosas existentes el elemento abismal se encuentra independiente del fundamento del ser, relativamente, originando así el carácter ambiguo de todas las cosas que existen. Posteriormente, ya radicado en Estados Unidos, Tillich sigue reflexionando sobre lo demoníaco y las demonías del presente, pero referidas ahora a las ambigüedades del progreso técnico y los avances en la carrera espacial y armamentista en el contexto de la guerra fría.

Ahondar más en esto excedería los límites de este artículo. Lo que importa es constatar que este original concepto de Tillich encuentra sus raíces en la visión religiosa de la realidad y de la historia originada en Lutero. Como afirma el mismo Tillich: "[el luteranismo] da cuerpo a la conciencia de 'corrupción' de la existencia [...] el conocimiento del carácter demoníaco irracional de la vida" ${ }^{12}$. Pero cuál es la solución al problema de lo demoníaco: es la gracia. Así como el pecador es justificado por la gracia, también las demonías son vencidas definitivamente y únicamente por la gracia: "La demonía se derrumba solo ante la divinidad; el estado poseído ante el estado de gracia, lo destructivo ante el destino redentor" 13 .

Se puede ver, entonces, que el principio protestante de la salvación por la gracia está en la base del pensamiento teológico de Tillich. Estos

12 'It embodies the consciousness of the 'corruption' of existence, $[\ldots]$ the knowledge of the irational demonic caracter of life). (P. TILLICH, The Interpretation ..., 54)

13 "Demonry breaks down only before divinity, the possessed state before the state of grace, the destructive before redeeming fate". ( P. TILLICH, The Interpretation..., 122) 
tres conceptos no son otra cosa que la expresión, o realización, del principio central del protestantismo. La teología de la cultura, centrada en la idea de la teonomía, la idea del kairos y el concepto de lo demoníaco, solo son posibles desde el principio protestante que acepta al hombre pecador tal como es, en la esperanza de ser justificado por la gracia. En palabras de nuestro autor: "En todas estas ideas -teonomía, el kairos, lo demoníaco [...], el principio protestante aparece en su poder revelador y crítico" ${ }^{14}$.

\section{EL PRINCIPIO PROTESTANTE Y LA SITUACIÓN PROLETARIA}

La reflexión tillichiana sobre el principio protestante y las ideas claves que de él derivan no quedaron en una mera reflexión sobre principios. Al contrario, a través de estos principios e ideas interpretó la realidad concreta que le tocó vivir. El ejemplo más concreto y significativo lo encontramos en su reflexión sobre lo que denominó como la situación proletaria. Aquí Tillich realiza una reflexión donde aplica explícitamente el principio protestante en un análisis de su situación social y cultural.

La experiencia de haber participado en el campo de batalla como capellán en la primera guerra mundial, en la cual le tocó presenciar en el frente la distancia entre los oficiales y el soldado común, el contraste entre las ganancias de los que se aprovechan de la guerra y las pérdidas del pueblo, las cargas sobre los hombros de la gente por aquellos que tenían el poder por haber nacido en distintas condiciones. Por otra parte, el experimento político de la República de Weimar, sumado esto al ambiente especial que se formó en Alemania una vez terminada la guerra produjo en Tillich una especial sensibilidad por la situación de la clase proletaria y una conciencia de estar viviendo un kairós que urgía a una unión entre el luteranismo y el socialismo.

En este contexto Tillich profundiza en el análisis del presente a partir del principio protestante. Sus reflexiones no las realiza como un político y un cientista social, sino como un teólogo luterano. Es principalmente en su ensayo de 1931 Protestantisches Prinzip und proletarische Situation (Principio protestante y situación proletaria) ${ }^{15}$ donde profundiza en la

\footnotetext{
14 "In all these ideas- theonomy, the kairos, the demonic, [...], the Protestant principle appears in its revealing and critical power" (P. TILLICH, The Protestant ..., xvii - xviii).

15 Publicado en inglés en P. TILLICH, The Protestant. ..., 161-181.
} 
relación entre estos dos términos: el principio protestante y la situación proletaria. La pregunta que nos planteamos aquí es ¿cómo Tillich enfrenta esta situación desde su identidad como protestante?, ¿cómo interpreta la historia, la situación presente, más en concreto, la situación proletaria, desde el principio protestante? Para responder esta pregunta es necesario destacar varios aspectos.

La situación proletaria debe ser entendida como la situación de la clase proletaria al interior del sistema capitalista cuyos miembros dependen del mercado de sus habilidades físicas para trabajar y cuyo destino es dependiente del movimiento del mercado ${ }^{16}$. El protestantismo, con el poder del principio protestante, debe ser capaz de entender esta situación, y para ello debe tomar conciencia de que esta situación no se explica solo por la simple finitud propia del hombre, sino que debe ser entendida como la manifestación de la finitud humana en el orgullo, la concupiscencia y su separación de su fundamento, es decir, el pecado original y sus consecuencias en la situación distorsionada del hombre en su condición de su autoextrañamiento. En efecto, Tillich realiza una interpretación religiosa de la situación proletaria, que significa una protesta profética como también una propuesta. Protesta contra cualquier ideología y utopía tanto de fuera de la situación proletaria como de dentro de los mismos movimientos revolucionarios; y la propuesta de la unión entre el luteranismo y el socialismo en vista de la transformación de la situación proletaria sometiendo todas sus decisiones y actividades al criterio del principio protestante.

Así pues, la situación proletaria, como consecuencia necesaria del carácter demoníaco del capitalismo, está sujeta a ser leída desde diversas ideologías. En virtud del principio protestante, el protestantismo protesta contra cualquier ideología presente tanto en el sistema capitalista, como en el proletariado, y como también del protestantismo mismo. El principio protestante nos previene de cualquier ideología, no solo de otras ideologías, sino también de las propias del mundo cristiano, entre las cuales se encuentra, según Tillich, la ideología católica, consistente en interpretar la doctrina de Dios hecho hombre para el interés del orden feudal, en el cual la Iglesia medieval formó parte; y la ideología humanista protestante en favor de los intereses de la victoria burguesa. Lo más peligroso de estas ideologías es su carácter inconsciente, que

16 Cfr. P. TILLICH, The Protestant ..., 164. 
puede llegar a ser objeto de fe y puede conducir al fanatismo. Una de las funciones más importantes del principio protestante es develar estas ideologías concretas, así como lo hicieron los profetas bíblicos respecto al orden social y religioso de su época. La situación proletaria tampoco está ajena a la creación de ideologías, por ejemplo al erigir una superestructura ideológica por sobre sus propios intereses, pero la situación proletaria objetiva, es decir las necesidades de una masa sociológicamente homogénea, destruye toda máscara ideológica. Así, la situación proletaria objetiva es una instancia para develar las ideologías, pues las necesidades humanas de la masa proletaria es el criterio para distinguir lo real de lo ideológico. Pero es la paradoja del principio protestante lo que previene de cualquier ideología, la paradoja del pecador justificado: el pecador es justificado, el hombre injusto es hecho justo delante de Dios, el hombre profano es santo, es decir que el juicio de Dios no responde a los logros humanos, sino que proviene de la infinita misericordia divina a pesar del pecado del hombre. Cuando esta relación divina-humana es comprendida y aceptada, todas las ideologías son destruidas. El hombre que acepta esto ya no tiene que engañarse a sí mismo sobre sí mismo porque él es aceptado como él es, con toda la perversión de su existencia. Sin que esto signifique una inmovilidad, porque ser aceptado por Dios significa también dejarse transformar por Él.

Por otra parte, el principio protestante previene también contra cualquier utopía. El principio protestante no espera la realización de una utopía, sino la anticipación de una realidad definitiva. La anticipación no es lo mismo que la ideología de la posesión, porque la realidad últimamente referida en toda genuina anticipación permanece siempre trascendente. Se trata de una realidad anticipada y trascendente que implica una exigencia de transformación, no de aceptación pasiva. Esta idea la expresa Tillich con lo que él denomina como el símbolo de la expectación. Se trata de la expectación profética que tensiona dos elementos: la promesa y la demanda, es decir, la tensión entre lo que es prometido, lo que $v a$ a venir, que no depende de la actividad humana y por otro lado lo que debe venir, que es demandado, es decir que será realidad solo por medio de la actividad humana ${ }^{17}$. Para Tillich la situación proletaria solo podría solucionarse por medio del socialismo que guiado por los criterios de

17 Cfr. P. TILLICH, The Socialist Decision (Harper \& Row Publishers, San Francisco, 1977) 104. 
la expectación profética podría superar los mitos del origen, propio de los nacionalismos, y la creencia en la armonía, propia de las demandas burguesas. En este sentido el socialismo, basado en el símbolo de la expectación profética, es en sí un movimiento profético ${ }^{18}$.

En resumen, la situación proletaria, en combinación con los conceptos de teonomía, kairos y demoníaco es, seguramente, el mejor ejemplo de cómo Tillich interpretó la historia y la cultura desde los criterios del principio protestante.

\section{EL PRINCIPIO PROTESTANTE Y EL PROTESTANTISMO}

Creo que lo dicho hasta aquí no deja en claro si el término principio protestante es referido al protestantismo, o a la iglesia protestante, o es más bien un principio abstracto sin ninguna realidad concreta. Es necesario detenerse en este punto.

Tillich hace una distinción entre el principio protestante y el protestantismo. Este último es una realización histórica del principio protestante; es, tal como nuestro autor lo denomina, la realidad protestante. Esto lo encontramos claramente expresado en la siguiente cita:

El protestantismo tiene un principio que permanece más allá de todas sus realizaciones. Es la fuente crítica y dinámica de todas las realizaciones protestantes, pero no es idéntico a ninguna de ellas. No puede ser delimitada por una definición. No se agota en ninguna religión histórica; no es idéntico a ninguna estructura de la reforma o de la cristiandad temprana o aún con cualquiera forma religiosa. Trasciende a todas ellas así como transciende cualquier forma cultural. Por otro lado, puede aparecer en todas ellas [...] El principio protestante es el juicio a toda realidad religiosa y cultural, incluyendo la religión y cultura que se denomina a sí misma 'protestante' ${ }^{\text {'19. }}$.

18 Cfr. P. TILLICH, The Socialist..., 109.

19 Protestantism has a principle that stands beyond all its realization. It is the critical and dynamic source of all Protestant realizations, but it is not identical with any of them. It cannot be confined by a definition.It is not exhausted by any historical religion; it is not identical with the structure of the Reformation or of early Christianity or even with a religious form at all. It transcends them as it transcends any cultural form. On the other hand, it can appear in all of them $[\ldots]$ the Protentant principle is the judge of every religious and cultural reality, including the religión and culture which calls itself "Protestant". (P. TILLICH, The Protestant..., 163. 
Como se puede ver, no es lo mismo el principio protestante que el protestantismo entendido como la realización histórica del primero. El principio protestante es eterno y un criterio permanente de todo lo temporal, mientras que el protestantismo es temporal y está sujeto al principio protestante, es juzgado por su propio principio, y este juicio podría ser negativo. Incluso la era protestante podría llegar a su fin, pero el principio protestante no sería negado. Al contrario, el fin de la era protestante sería otra manifestación de la verdad y el poder del principio protestante.

Ahora bien, el principio protestante debe ser entendido no solo como una doctrina fundamental sobre la justificación por la gracia, sino también como una actitud de protesta profética. Aquí nos encontramos, entonces, con una seria paradoja, que se podría plantear de la siguiente manera: si el principio protestante implica la protesta contra cualquier realidad concreta que pretenda identificarse como la gracia misma y la negación de la seguridad de toda posesión humana incluyendo la religión y la Iglesia ¿cómo puede ser posible que el principio protestante se identifique con el protestantismo en cuanto realidad histórica?, ¿puede el principio protestante crear formas?, o dicho con el lenguaje de Tillich, ¿puede el principio protestante contener en sí un poder formativo? Este problema no es indiferente para Tillich. Se podría plantear por medio de la siguiente pregunta:¡cómo puede el poder formativo del principio protestante y la protesta contra la forma, propia del principio protestante, vivir juntos en una iglesia?

Para contestar esta pregunta es necesario ir por parte. El principio protestante no podría hacer efectiva su protesta profética sin una realidad histórica desde donde realizarla, necesita una estructura. Nuestro autor se refiere a esta estructura con el término Gestalt, significando con esto una estructura completa de una realidad viva, tal como una persona individual, un grupo individual o un cuerpo biológico ${ }^{20}$. Pues bien, el principio protestante no podría realizar su protesta sin una Gestalt a la cual pertenece. La paradoja es que el principio protestante tendría que protestar contra su misma Gestalt, puesto que el principio protestante implica la protesta contra toda forma o Gestalt que pretenda identificarse con la gracia. Luego entonces, si inevitablemente el principio protestante necesita una forma, o Gestalt, para realizar su protesta profé-

20 Cfr. P. TILLICH, The Protestant..., 206. 
tica contra toda forma, entonces hay que contestar una nueva pregunta: ¿cuál es la Gestalt desde donde el protestantismo protesta sin destruir su propio fundamento?

Esta pregunta es respondida en el ensayo The Formative Power of Protestantism (El poder formativo del protestantismo) ${ }^{21}$. Nuestro autor encuentra la respuesta en la misma fe. Pues esta última tiene que ser entendida como una estructura divina de la realidad. Es estructura porque se hace efectiva en el hombre. La Palabra es dicha desde más allá de nosotros a nosotros, la gracia viene hacia nosotros y es recibida por nosotros, de manera que en cierto sentido deja de ser trascendente, se hace inmanente, es objetiva. Así, la Palabra crea la fe como un poder formativo de una vida personal y una comunidad. Se puede decir, en este sentido, que la fe se hace estructura, se hace Gestalt. Tillich sigue ahondando aún más: la fe es producto de la gracia, entonces la Gestalt desde donde el protestantismo protesta sin destruir su propio fundamento es lo que él denomina como la Gestalt de la gracia. Por Gestalt de la gracia hay que entender las formas finitas a través de las cuales aparece lo divino; son formas finitas, por así decirlo, seleccionadas por la gracia para aparecer a través de ellas, como por ejemplo la debilidad de la Iglesia y fundamentalmente la humanidad de Cristo. En este punto Tillich realiza fuertes críticas a la Iglesia Católica en cuanto que, según él, el catolicismo cae en el error de identificar algunas formas concretas con la misma gracia, como la doctrina, los sacramentos y la autoridad pontificia; pero también desliza algunas críticas al propio protestantismo histórico con respecto a la posesión ortodoxa de la Palabra infalible de Dios, la doctrina pura y la posesión científica de Jesús histórico.

Resumiendo, la estructura, o Gestalt, sobre la que se basa el protestantismo para su protesta contra cualquiera estructura idolátrica, es la fe recibida por el hombre, que se hace comunidad, se hace Gestalt de la gracia, una Gestalt que a través de su misma realidad transparenta la gracia sin atarse a ninguna forma determinada, ni siquiera a la Iglesia.

Ahora bien, la Gestalt de la gracia no es una realidad separada del mundo, si fuera así se caería justamente en lo que el protestantismo protesta. La Gestalt de la gracia elige algunas formas del mundo para transparentar la gracia; surge entonces la pregunta sobre la relación del

${ }^{21}$ Publicado en P. TILLLICH, The Protestant..., 206-221. 
protestantismo con lo secular. Pues bien, el principio protestante y su realización histórica en una Gestalt de la gracia plantean una relación particular con lo secular, puesto que el poder formativo del protestantismo no se limita al ámbito eclesial, se realiza también en lo secular. En este contexto Tillich habla del secularismo protestante como un elemento necesario de la realización protestante. En efecto, el secularismo no es sinónimo de ateo o no religioso. En lo secular se puede expresar una religión latente, porque lo finito expresa lo infinito indirectamente. El protestantismo ve al secularismo como una tarea de su poder formativo; ve en las manifestaciones culturales unas formas de expresión de la sustancia religiosa. Es por eso que el protestantismo debe estar atento a las manifestaciones culturales, como las artes, la filosofía, la política, respetándolas como tales, sin sacralizarlas. El protestantismo debe dejarse cuestionar por el elemento secular y debe estar atento a las manifestaciones indirectamente religiosas en lo secular a través de las expresiones poéticas, científicas, éticas. Esta especial relación con lo secular previene al protestantismo contra cualquier sistema eclesiástico que termine siendo identificado con lo Incondicionado al cual apunta.

Se puede concluir aquí que la estructura sobre la que se sostiene el principio protestante es la Gestalt de la gracia, pero esta última tampoco se puede identificar con el protestantismo como una realidad histórica; la Gestalt de la gracia trasciende a la Iglesia. Lo afirma claramente nuestro autor en su ensayo Protestantism as a Critical and Creative Principle (El protestantismo como un principio crítico y creativo) "...la iglesia visible es esencialmente una forma de la gracia, pero esto no significa que tiene una forma tangible, objetiva. La iglesia no tiene la forma de la gracia a su disposición. La forma de la gracia no puede ser la base de ningún 'sistema' o de ninguna pretensión jerárquica" ${ }^{22}$.

Siempre va a existir una distancia entre el protestantismo histórico, la Gestalt de la gracia y el principio protestante. Es necesaria esta distancia propia de la crítica profética ante cualquier realidad secular y eclesial. Por tanto el protestantismo también debe someterse a la crítica proféti-

22 "...the visible church is assentially a form of grace, but this does not mean that has a tangible, objective form. The church does not have the form of grace at its disposal. The form of grace cannot be the basis of any 'system' or of any hierarchical pretense” (P. TILLICH, Political Expectation [Mercer University Press, Macon, 1981] 24). 
ca del propio principio protestante. Pero el principio protestante no es solo protesta, su criticismo tiene un punto final que hace posible que la Gestalt de la gracia pueda vivir. Este punto final es el poder del Nuevo Ser manifestado en Jesús el Cristo. Aquí la protesta protestante llega a su fin. Este es el fundamento del principio protestante y de la realidad protestante.

\section{5. ¿CUÁl ES EL FUTURO DEL PROTESTANTISMO?}

El futuro del protestantismo ha sido una preocupación importante para nuestro autor. En un ensayo publicado con el título The End of the Protestant Era? ${ }^{23}$ planteó la posibilidad del fin de un período temporal caracterizado por la presencia del protestantismo actual, es decir, el fin de la era protestante. Puede que el protestantismo no sobreviva al colectivismo producto del capitalismo tardío. En efecto, según Tillich, las innovaciones tecnológicas y las organizaciones capitalistas han creado vastas masas que habitan las grandes ciudades de todos los países civilizados. Se trata de una desintegración de la vida personal, en que los grupos y las personalidades son suplantadas por actitudes de masa idénticas; una situación caracterizada por el olvido de las tradiciones; la pérdida del poder de los viejos símbolos; el sin sentido de la existencia; la sumisión a las leyes del mercado, a pesar del discurso moderno de la libertad individual. El individuo se encuentra disuelto en una masa amorfa que se rige según las leyes que operan en la sicología de las masas. Esta desintegración, que hunde sus raíces en la moderna sociedad industrial, está siendo realidad ${ }^{24}$.

Pues bien, Tillich afirma que el protestantismo está en completa contradicción a esta tendencia ${ }^{25}$. Se hace difícil su supervivencia en la situación actual, por tres razones. En primer lugar, en el protestantismo es fundamental la decisión personal. Cada protestante, cada laico, cada ministro debe decidir por sí mismo si una doctrina es verdadera o no; para el protestante la Biblia es objeto de su interpretación personal; en el protestantismo no hay doctrina ni sacerdotes, ni poder, ni autoridad

23 En P. TILLICH, The Protestant ..., 222 ss. Publicado originalmente con el título Protestantism in the Present World Situation, en American Journal of Sociology, XLIII (1937).

24 Cfr. P. TILLICH, The Protestant ..., 223-225.

25 Cfr. P. TILLICH, The Protestant ..., 226. 
eclesial. Por eso para el protestante es imprescindible la decisión personal, pero en la actual situación de la disolución de la personalidad en la masa nos encontramos prácticamente inhabilitados para tal decisión. El protestantismo parece ser parte de esta desintegración. Un segundo aspecto es que el protestantismo, a causa de su proceso de racionalización de la doctrina, ha disuelto el misterio religioso cada vez más. Pues como consecuencia del principio protestante, el protestantismo es una religión altamente intelectualizada. En el protestantismo no hay sacerdotes, sino predicadores cuya autoridad no es sacramental, sino que proviene de su cualidad intelectual y moral; ellos apelan al intelecto. Pero las masas desintegradas necesitan símbolos que sean inmediatamente comprensibles sin mediación del intelecto. Además que la educación protestante ha sido capaz de educar a individuos selectos, pero ha fallado en la educación de las masas. El tercer aspecto es la falta de una jerarquía independiente en el protestantismo. Esto hace que sea prácticamente imposible ser independiente del Estado, entonces la existencia social del protestantismo depende enteramente del apoyo del Estado y de algunos grupos de poder. En los períodos de desintegración esto significa la desintegración de la iglesia misma.

Tillich ensaya una suerte de diagnóstico social y cultural que corresponde a la sociedad europea y norteamericana de finales de los años 30. Pero a pesar de esta distancia temporal, creo que las características señaladas también reflejan a nuestra sociedad globalizada actual. La pérdida de significado de las tradiciones, el descrédito de las instituciones, la erosión de los símbolos y ritos caracterizan a nuestra sociedad de hoy. Es una sociedad masificada por los medios de comunicación y la revolución digital, y al mismo tiempo individualizada, pero como bien dice el sociólogo Ulrich Beck, se trata de una individualización que está regida por las leyes del mercado, sobre todo del mercado laboral. Creo que Tillich planteó, hace más de 70 años, algunos rasgos sociales y culturales que se han ido acentuando en el tiempo. Su visión es válida también para hoy, por tanto, me atrevería a afirmar que el desafío que planteó al protestantismo de su tiempo es también el desafío para el protestantismo de hoy.

Ahora bien, frente a esta situación social y cultural Tillich se plantea la pregunta: ¿qué posibilidades de sobrevivencia existe para el protestantismo? Según él, el protestantismo podría sobrevivir venciendo los 
siguientes tres desafíos: primero, el protestantismo requiere realizar una nueva comprensión de los símbolos y todas de las cosas sagradas. Esto significa reformular sus formas de vida, sus ritos, su constitución, sus éticas sociales e individuales, de manera que pueda ser aceptado hoy el mensaje que se quiere entregar. Lo segundo consiste en aprovechar una condición que proviene de la misma naturaleza de la actitud protestante, su recurso para tratar con el mundo secular en una manera más diferenciada y más directa que el catolicismo y cualquier otra religión. Esto porque el protestantismo niega en principio la separación entre la esfera sagrada y la esfera profana. Todo es profano en sí mismo, y solo puede existir lo sagrado en la medida que algo es convertido en un símbolo de lo divino. El tercer desafío es ejercer la más importante contribución del propio protestantismo: la protesta profética contra cualquier poder que demanda carácter divino por sí mismo, es decir, la protesta contra los abusos de las autoridades centralizadas y los poderes que se desarrollan bajo las exigencias del nuevo colectivismo. Sin la protesta profética los poderes y las nuevas autoridades conducirán a la sociedad hacia una desintegración de mayor alcance. Se necesita la protesta profética del protestantismo. Para una efectiva sobrevivencia se requiere que el protestantismo desarrolle estas tres líneas.

Pero Tillich continúa preguntándose dónde están los protestantes hoy, y qué están haciendo para enfrentar estos desafíos. Él identifica dos acciones de grupos concretos: están aquellos que se mantienen en una actitud defensiva, construyendo una especie de reserva religiosa, centrándose en sus dogmas y concibiendo una revelación trascendente sin relación con lo temporal -a este respecto Tillich reflota su repetida crítica a la mal llamada, según él, teología dialéctica de Karl Barth-. La estrategia consistiría en una especie de reserva análoga a las reservas indígenas que han sobrevivido en Estados Unidos. Existen otros grupos dentro del protestantismo que están tratando de introducir ciertos elementos del catolicismo, como una nueva comprensión de los sacramentos, un enriquecimiento de los ritos, la autoridad episcopal. El problema es que este intento termina siendo una especie de imitación que no corresponde con el sentimiento tradicional del protestante. Tillich propone un tercer camino, una nueva fundación basada en el principio profético del protestantismo y su capacidad para tratar directamente con el mundo secular, “...Esta tercera vía requiere que el protestantismo aparezca como el espíritu profético que señalará su inclinación, sin condiciones eclesiásti- 
cas, organización y tradiciones"26. Esto puede operar a través de corrientes políticas, movimientos, o incluso la Iglesia Católica. Pero, para que no quede en una demanda idealista, se requiere un grupo que sostenga este espíritu. Según nuestro autor, este grupo tendría que cumplir las siguientes condiciones: una decisión en favor del principio protestante en la interpretación de la existencia humana, sin tener que pertenecer necesariamente a una iglesia protestante, o incluso iglesia cristiana, ni a un partido político o filosófico; una decisión por un programa fundado sobre el principio protestante, y una decisión por programas especiales que contengan la aplicación del programa general para distintos grupos, iglesias o naciones ${ }^{27}$.

\section{A MODO DE CONCLUSIÓN: PERSPECTIVA ECUMÉNICA}

Creo que la conmemoración de los 500 años del inicio de la reforma protestante puede ser una buena oportunidad para un diálogo ecuménico fructífero con la Iglesia Católica, sin quedarse en aspectos difíciles, pero muchas veces secundarios, o en las coyunturas históricas que contextualizaron la lucha de Lutero; aunque, al mismo tiempo, sin desconocer las importantes diferencias que nos separan. Sería de gran ayuda hacer el esfuerzo de comprender los elementos más esenciales que han inspirado el desarrollo histórico del protestantismo. Tillich puede hacer un gran aporte en este sentido. Sus reflexiones constituyen una fuente que nos podrían proporcionar algunas pistas efectivas para el diálogo ecuménico entre el protestantismo y el catolicismo sobre la base de la comprensión de sus principios.

En efecto, Tillich realiza una comprensión radical del principio protestante, distinguiéndolo del protestantismo como realidad histórica. El principio protestante es el fundamento del protestantismo, y al mismo tiempo lo trasciende. Por otra parte, se refiere a la sustancia católica como elemento central del catolicismo, indicando con esto "la encarnación

\footnotetext{
26 "This third way requires that Protestantism appear as the prophetic spirit which lists where it will, without eclesiastical conditions, organization, and traditions" (P. TILLICH, The Protestant..., 232).

27 Cfr. P. TILLICH, Protestant ..., 230 ss.
} 
concreta de la Presencia Espiritual"28, es decir, el carácter sacramental del catolicismo.

El principio protestante ha estado presente de muchas maneras en el catolicismo, y viceversa, el protestantismo reconoce la necesidad de la sustancia católica, de fortalecer sus símbolos y la dimensión sacramental. Ambos, el principio protestante y la sustancia católica se han yuxtapuesto y combinan a lo largo de ambas historias.

Cabe mencionar el influyente libro del teólogo Jaroslav Pelikan, Obedient Rebels: Catholic Substance and Protestant Principle in Luther's Reformation (Rebeldes obedientes: la substancia católica y el principio protestante en la reforma de Lutero). Este escritor describe la sustancia católica como "el cuerpo de tradición, liturgia, dogma, y feligresía desarrollado principalmente por la iglesia antigua y encarnado (pero no agotado) para Lutero en la Iglesia católica romana de sus días" ${ }^{29}$. Él, inspirado por Tillich, plantea las diversas combinaciones entre el principio protestante y la sustancia católica en la reforma iniciada por Lutero, y también la presencia del principio protestante en la Iglesia católica. Es oportuno citar aquí algunas de sus palabras:

...la paradoja de la sustancia católica y el principio protestante en la reforma de Lutero se corresponden con la necesidad de ambos el protestantismo y el catolicismo romano para esta misma combinación. La reforma litúrgica en el catolicismo romano no puede dejar de pensar en Lutero, los estudios protestantes sobre el culto continuamente se preguntan si la pérdida de la sustancia católica no ha empobrecido la espiritualidad protestante desde la reforma. Para Paul Tillich los términos 'sustancia católica' y 'principio protestante' fueron básicos en el vocabulario de la teología sistemática; Karl Barth se vio obligado a mirar más cercanamente la sustancia católica detrás de su pensamiento. Y un movimiento ecuménico que comenzó como una solución protestante a un problema protestante ahora incluye no solo la sustancia católica del oriente ortodoxo en sus discusiones

28 "...the concrete embodiment of the Spiritual Presence" (P. TILLICH, Systematic...III, 245)

29 “... the body of tradition, liturgy, dogma and churchmanship developed chiefly by the anciente church and embodied (but not exhausted) for Luther in the Roman Catholic Church of his day" (J. PELIKAN, Obedient Rebels: Chathilic Substance and Protestant Principle in Luther's Reformation [Harper\&Row Publishers, New York, 1964] 13). 
sobre la Iglesia y su unidad, sino que también el catolicismo romano. Entonces Lutero, el rebelde obediente, y la reforma que inauguró exponen la herencia católica y la reconstrucción protestante en una forma que continúa siendo relevante para la vida y pensamiento de la entera comunidad cristiana ${ }^{30}$.

La comprensión del principio protestante y de la sustancia católica podría ayudar para un mayor acercamiento en el encuentro ecuménico. Un encuentro que se ha hecho efectivo, aunque no hemos sido muy conscientes de ello, a partir del Concilio Vaticano II, que, sin duda, ha integrado varios elementos del principio protestante, como el interés por acudir a las fuentes bíblicas, el lugar profético crítico de la Iglesia en el mundo y la mayor horizontalidad de los integrantes del Pueblo de Dios en virtud del bautismo. Y viceversa el protestantismo, ya más alejado del fragor de la lucha de Lutero, se encuentra en camino de revalorizar la dimensión sacramental simbólica de la fe. Esta línea de reflexión ecuménica claramente expresada en 1964 por el teólogo estadounidense Jaroslav Pelikan podría seguir profundizándose, para la vida y el pensamiento de la entera comunidad cristiana.

30 "...the paradox of Catholic substance and Protestant principle in Luther's Reformation is matched by the need of both Protestantism and Roman catholicis for this very combination. Liturgical reform in Roman Catholicism cannot get its mind off martin Luther; Protestant studies of worship continually inquire whether the loss of Catholic substance has not impoverished Protestant spirituality since the Reformation. Paul Tillich has made the terms 'Catholic substance' and 'Protestant principle' basic to the vocabulary of systematic theology; Karl Barth has foun himself obliged to lok more closely at the Catholic substance behind his thought. And an ecumenical movement that began as a Protestant solution ot a Protestant problema now includes not only the Catholic substance of Eastern Orthodoxy in its discussions of the church and its unity, but Roman Catholicism as well. Thus Luther, the obedient rebel, and the Reformation he inaugurated set forth both Catholic heritage and Protestant reconstruction in a form that continues to be relevant to the life and thought of the entire Christian community" (J. PELIKAN, Obedient..., 23-24). 


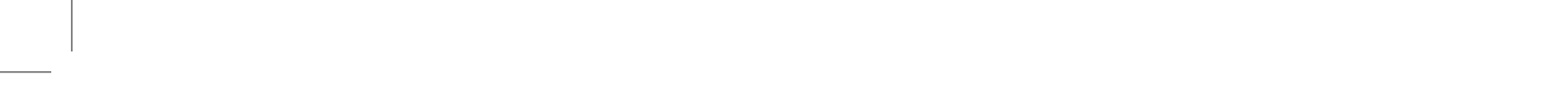

